\title{
Talking to Ourselves Internal Communication Strategies for Reference Services
}

At many academic libraries, spiral notebooks and three ring binders have given way to blogs and wikis as a means of facilitating communication at the reference desk. Western Kentucky University Libraries opted instead to create a custom internal website to log reference transactions, highlight current issues, and manage scheduling changes. This solution incorporated numerous platforms and technologies, including LibGuides, Facebook, and Google Calendar. It avoided some of the pitfalls described in the literature, such as relying too heavily on user-generated content, and has been successful largely because it is embedded in the reference workspace and contains features that librarians will use on a daily basis.

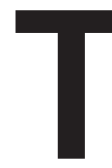

he stock in trade of library reference services is knowledge. No one is better trained to find and retrieve the appropriate information than a good reference librarian. It is strange then that, for all of our skill in guiding others to obscure facts and resources, one of the thorniest problems we deal with in reference is internal communication, learning to effectively document and distribute the many bits of information, news, and procedural changes we need for effective reference services. Even in small libraries, it is a challenge to ensure that all reference staff—often working evening or weekend hours when regular staff members are not present-stay fully informed of important changes. These difficulties only mount in larger libraries covering multiple floors, buildings, and campuses.

Traditionally, the internal communications needs of library reference were fulfilled, if not by simple word of mouth, then by a wide variety of paper contraptions and contrivances (see Bejune and Morris for an excellent review). ${ }^{1}$ Most common, perhaps, was the ubiquitous reference notebook. Spiral-bound or loose-leaf, in greater or lesser detail, this fixture of the reference desk was the instant messaging system of its day. It allowed staff to write down events and updates relevant to the reference desk. It could also include notes and discussions passed to and fro among the staff. Many libraries provided sections within the notebook for necessary and hard-to-find information, such as specific policies, special holiday hours, phone numbers, and perhaps even some common reference items. As long as everyone wrote everything down in the notebook, and as long as everyone read it, the news moved on. Predictably, the results were spotty but adequate for the purpose and the times. In recent years, however, we

\section{John Gottfried, Laura DeLancey, and Amanda Hardin}

\author{
John Gottfried (jcgottfried@ \\ alumni.iu.edu) is Reference Services \\ Coordinator at Western Kentucky \\ University, Bowling Green, Kentucky. \\ Laura DeLancey (laura.delancey@ \\ wku.edu) is Electronic and Continuing \\ Resources Coordinator at Western \\ Kentucky University. Amanda Hardin \\ (amanda.hardin@wku.edu)is \\ Reference Services Specialist at \\ Western Kentucky University.
}

Reference \& User Services Quarterly, vol. 54, no. 3, pp. 37-43 (c) 2015 American Library Association. All rights reserved.

Permission granted to reproduce for nonprofit, educational use. 


\section{FEATURE}

rely on the computer more and more for information and communication, and the reference desk is no exception.

In most libraries, the bulk of the information formerly entered in the old paper notebook has been gradually absorbed into the library website. The library website normally includes access to online library catalogs and electronic resources, information about the library, and much more. As useful and informative as it is, however, the library website cannot supply all of the knowledge needed by library staff. The library website is designed, or should be, to serve the library's patrons, not the staff. Many internal arguments about the content of library websites arise from misunderstandings about this simple fact. At Western Kentucky University Libraries, for example, a recent website usability study revealed that our users prefer that we provide links to only the most popular resources, using simple, easy-to-understand terms. Our librarians, on the other hand, consistently ask for links to very specific resources, forms, and documents. We realized that our librarians and reference staff needed a site offering resources specific to their needs-procedural documents, staff schedules, internal services, and the like-entirely separate from the site we present to the public. In other words, it was time to move beyond the yellowed reference notebook and patron-focused library website to create a quick and informative set of resources customized to the needs of the reference staff.

\section{INTERNAL COMMUNICATION FOR REFERENCE SERVICES}

Internal webpages have become increasingly common both in libraries and in businesses of all sizes in the past couple decades. Initially, static intranets were the most common form, but they can fall prey to the same issues that render the reference desk notebook impractical: infrequent updates and poorly-curated pages resulting in out-of-date or erroneous information. The prevalence of Web 2.0 technologies such as wikis and blogs added a more collaborative dimension to library intranets, and they have been widely used to replace static intranets and notebooks.

Starting a blog requires little initial investment in terms of cost or training, and because posts are organized chronologically and can be edited by multiple users, they are a logical digital means of logging reference transactions and tracking current issues. According to McIntyre and Nicolle, successful blogs can be a useful knowledge management tool for gathering best practices and other information. ${ }^{2}$ When blogs fail, it is often due to lack of participation; users do not add posts, comments, or read the blog with enough frequency to keep it alive, as discussed in Costello and Del Bosque and Rodriguez. ${ }^{3}$ In order to improve internal communication, blogs require frequent updates and buy-in from all users to succeed: Costello and Del Bosque found that new technologies not only need to be adopted, they must be "integrated into the workflow of the organization." ${ }^{\prime 4}$ Old habits die hard, and some libraries found that adding email notifications to new posts helped users incorporate this new medium without changing their work habits. ${ }^{5}$ In this scenario, the blog format added the ability to consolidate and easily retrieve old posts.

Blogs can be a valuable asset to the reference desk, replacing printed desk logs or mass emails as a way to facilitate internal communication. But because they always highlight newer items, they are best suited for transient issues: they may replace a reference desk log but not the entire binder. Many libraries that have already taken the first step towards consolidating institutional information in an intranet are discovering that wikis offer a more flexible, collaborative, and user-friendly interface.

Both the University of Nevada in 2007 and the University of Alabama Libraries in 2009 transitioned to wiki-based intranets, with great success: at Alabama, monthly usage increased ten-fold over the old intranet, ${ }^{6}$ and at Nevada, 97.4 percent of staff members reported using the wiki, over half of them on a weekly basis. ${ }^{7}$ The staff of the Univeristy of Houston Music Library accomplished one of the more successful wiki implementations in terms of usage and functionality. ${ }^{8}$ In 2006, they created an internal wiki containing policies and procedures, problem logs, discussion forums, and the tools needed to manage student activities and track their gate count. Perhaps because it has so many quotidian functions, staff members visit the wiki's pages frequently and have continued to update them as needed. Of course wikis, like blogs, can fail due to lack of use or participation, ${ }^{9}$ but they require less of a commitment to creating new content.

Blogs, wikis, online FAQs, and digital newsletters have the potential to vastly improve internal communication. They are readily updated and edited by multiple users, thereby reducing the burden on IT staff, ${ }^{10}$ and encouraging library staff to participate in their own knowledge management. ${ }^{11}$ The success of any new technology hinges on the willingness of librarians to incorporate that technology into their workflow. Redundancy (duplicating intranet content in a more familiar form, such as email) and functionality (including essential functions, such as a gate count or transaction log) can encourage both participation and adoption.

\section{OUR GOALS}

Western Kentucky University (WKU) Libraries serve 17,500 undergraduate and almost 3,000 graduate students. We have over 750,000 catalogued monographs and a staff of ninetyseven. Library collections and staff are spread over seven locations: the main library, the Visual and Performing Arts Library, the Education Library, and Special Collections on the main campus in Bowling Green, as well as regional campuses in Glasgow, Elizabethtown, and Owensboro. In 2012 we began planning a new Information Commons on the main campus, and this prompted us to reevaluate all of our reference services, among them our means of internal communication.

We decided that we should develop a new source of information for the WKU reference staff, and we decided to 
base our goals on a few simple, practical needs. We started, for example, with a goal of making materials from the old reference notebook available online because we needed to make materials available in several locations within the main library (reference desks, periodicals room, the Visual and Performing Arts Library) and at other WKU campuses. We further decided that our new resource must (1) permit effortless access from any location; (2) provide the ability to make fast, easy updates for news and information; and (3) deliver useful data to monitor usage and activity. These goals were in line with objectives set by the coordinator of Reference Services and with library-wide objectives to make services available throughout the WKU system. The WKU Libraries had already used Springshare's LibGuides, a flexible content management system, to create over one hundred research guides. LibGuides offers a fairly intuitive, what-you-see-iswhat-you-get interface, and each page has adjustable privacy settings and editing and administrative permissions. Because our librarians had used this tool when creating their research guides, they were already used to the look and feel of these webpages. Because we wanted the new resource to be available online, the creation of a customized LibGuide for this purpose seemed the most efficient solution, as it required no additional expense or training to use this platform for our updated reference resource. It would also allow us to revise the new page frequently and easily, which we considered critical in light of the experimental nature of the project.

\section{OUR SOLUTIONS}

We assembled the Reference Home page during the summer of 2012. Since our librarians work on a ten-month contract with two months off in the summer, we did not have the opportunity to gather extensive input from many of the librarians. We did hold discussions with those few librarians and staff who were available, and there were a number of conversations among the small group working on the new page. Lacking comprehensive feedback from our colleagues, however, we approached the new page as a pilot project open to substantial revision when we presented it to our librarians and our users. We began by creating electronic reproductions of content from the old reference notebook and other paper materials kept at the reference desk: phone directories, maps, schedules, forms, policy documents, etc. To this we added one-click access to frequently-used electronic resources, including the library catalog, research databases, and other electronic resources approximating the old ready reference collection (dictionaries, almanacs, writing style guides, and the like).

We continued to test and revise the Reference Home page throughout the summer, obtaining input from a small number of student assistants, library staff members, and a few librarians. At the suggestion of the students, for example, we added a student assistant page to post task lists, rules, and procedural documents specific to them. The librarians, on the other hand, asked that we include links to frequently

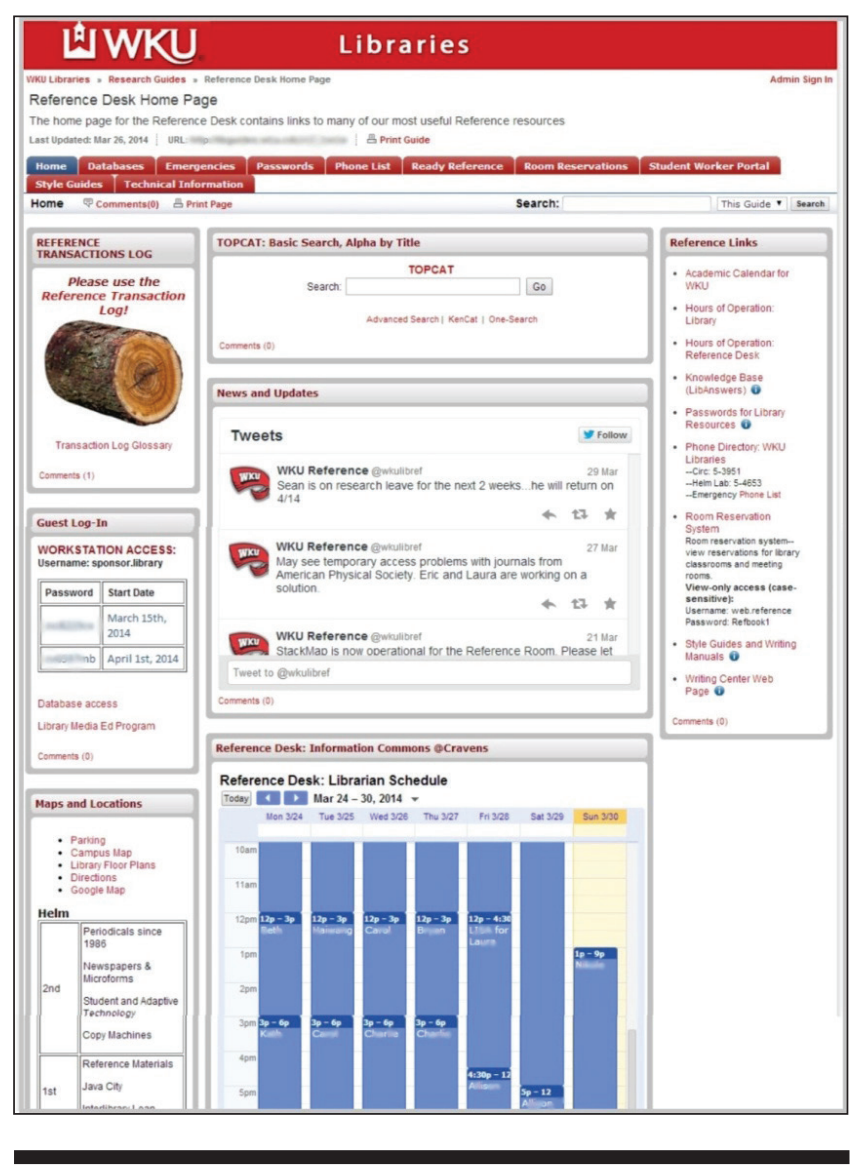

Figure 1. Reference Home Page

requested resources, such as the campus Writing Center and the university's academic calendars. As we neared the beginning of the fall semester more of our librarians returned, and we interviewed them individually about the new page, incorporating their input wherever possible. We went live at the beginning of the fall semester, making Reference Home the home page for all Internet browsers on all reference desk computers (see figure 1).

In addition to the page's static content (hours, link to existing resources, phone lists), we included several dynamic features that would both improve efficiency and encourage our librarians to adopt this new resource and integrate it into their workflow. These features are discussed below.

\section{Reference Transaction Log}

One of the most important functions of Reference Home is the reference transaction log. We used Springshare's LibAnalytics to collect data on services performed at the reference desk. Librarians simply have to click a large, obvious transaction icon button each time they are asked a question in order to record the time, location, medium (phone, email, in-person, etc), and type of question (directional, advanced reference, printer assistance, etc.). This produces much richer data than the old tick marks system, and LibAnalytics allows us to 


\section{FEATURE}

generate charts, graphs, and filtered data sets with minimal effort. To help ensure consistency, we added a transaction log glossary offering definitions of the different kinds of reference questions, such as basic versus advanced reference).

\section{Reference Desk Schedule Calendar}

It is important that reference staff always know who is scheduled for coverage and who has traded coverage with whom. In the past we used a paper calendar at the reference desk for this purpose, but not all of the trades made it to the calendar, and not everyone remembered the trades they had made. To prevent misunderstandings and to allow our reference staff to view the schedule at any time, from anywhere, we created a Google Calendar specifically for the reference desk. We decided on Google Calendar because it was readily available, free, and easy to use. Google Calendar makes it easy to embed a calendar widget on any web page. When changes are made to the Google Calendar it updates the widgets automatically, and this has helped to reduce scheduling confusion. The Google Calendar was created on an institutional account, and only the reference coordinator and the reference specialist need to access it, so there were no privacy concerns with personal Google accounts. The effectiveness of this calendar encouraged us to create a second Google Calendar for reference student assistants. The student assistants do not have to use their personal Google account to access this calendarthey have access to a shared general account we created to manage it. Given the frequency with which student assistant schedules change, the flexibility obtained with this approach was invaluable in in keeping student assistant schedules organized and up-to-date.

\section{Twitter Feed}

Keeping the reference staff aware of relevant changes, news, and events was another challenge. When a library research database was malfunctioning, for instance, or if a staff member called in sick, it was important to get the information out quickly. It was frequently the case that these situations arose at times when we were least able to access a computer to make the appropriate postings. Using the same criteria that guided our choice of calendar - free, easy, and available —we decided to use Twitter to feed updates to the Reference Home page. We set up a reference account on Twitter, and when there is a need to post quick announcements, we simply send tweets to a widget on the Reference Home page. Tweets can, of course, be sent from smart phones, so it is now an easy matter to get the word out to reference staff nearly instantly.

\section{Room Reservation System}

A small number of classrooms, conference rooms, and computer labs within WKU Libraries are available for staff reservations. Traditionally the room reservation notebook was kept at the reference desk, but many of the rooms are spread across the different floors and buildings that make up the libraries. Again we decided to place the room reservation system online. We tried to use Microsoft Outlook as an online room reservation system, but many of our librarians found it difficult to set up and use on their computers. We also received complaints about minor but annoying performance issues: several instances of double-booked rooms arose, for example, and in other cases room reservations apparently disappeared from the system. After a lengthy search, the Library Systems Office found and obtained permission from the Information Technology administrators to set up Online Resource Sharer, a free share-ware system that allowed us to create and view room reservations at any time from any location. This reservation system is only available to library faculty and staff, so other members of the campus community must coordinate with someone at the library in order to use our facilities. Non-library faculty or staff simply need to contact the librarian assigned to their specific college or department (subject specialist librarians are assigned to each of the university's colleges) to request a reservation. Library classrooms may only be reserved for library-related activities (library instruction or library research), and all reservations are assigned on a first-come, first-served basis.

\section{SAME GOALS, DIFFERENT IMPLEMENTATION}

In the months after the Reference Home page was up and running, we realized that our reference student assistants had communication needs entirely separate from the regular employees. The students required a faster, more direct way to communicate-they frequently needed to trade schedules on short notice, or we needed to let them know about changes or emerging events at the library very quickly. Students often checked their school email accounts on a sporadic basis, and phone messages led to endless rounds of phone tag (leaving messages in response to messages). The supervisor of our student assistants identified a very creative approach to this problem, setting up a Facebook group composed only of our student assistants and their supervisors. While students tend to check email only occasionally, they can and do check Facebook on a near-constant basis. The students were also more comfortable communicating with each other in this format, and the potential for give-and-take in the comments section made working out arrangements for coverage easier.

\section{RESULTS}

\section{Reference Home Page Usage and Perceptions}

Usage for Reference Home has been heavy (averaging several thousand hits per month) primarily because it is the home page for all Internet browsers on the staff computers at the reference desk. Reference staff must access Reference Home, moreover, to enter reference transactions in the online log, and all reference staff share a strong desire to maintain an 


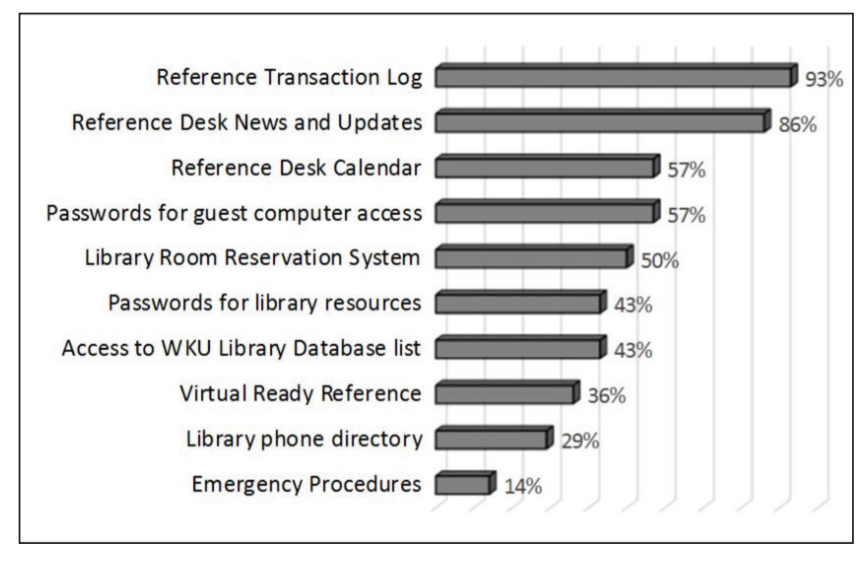

Figure 2. Percentage of Reference Staff Using Various Resources from the Reference Home Page

accurate record as evidence of the work that is done at the reference desk. This constant, enforced exposure to Reference Home appears to have helped the staff to become at least somewhat more comfortable with its functions and content.

Initial reaction to the Reference Home page was generally favorable, though the conversion from paper to electronic resources was easier for some than others. When the page had been functioning for about eighteen months, we surveyed the reference staff to gauge their perceptions of Reference Home and gather their suggestions for improvement. The survey (see appendix) was distributed in February 2014. A link to the online survey was sent to seventeen reference staff members, fourteen of whom completed it.

Overall perceptions of the usefulness of the Reference Home page were positive-the average rating was 8.2 on a 10-point scale rating where 1 was "not useful" and 10 was "very useful." We asked our staff which resources on Reference Home they used most often. All respondents indicated that they used the Reference Home page to register their reference transactions, and respondents all estimated that they are capturing over 90 percent of the transactions they perform. Other popular resources on the Reference Home page include News and Updates and the Reference Schedule Calendar (see figure 2).

When asked for specific likes, dislikes, and suggestions, our reference staff found little consensus. While most found the page helpful, one person felt the page was an annoyance and preferred working with the library webpage (though the two do serve different functions). Some felt the page was cluttered and had too much text, while others wished there was more content. Some comments indicated a lack of familiarity with the content of the page-a request for a link to the library catalog was baffling, for example, since the link to the library catalog is the first item on the page. Some found illustrations or icons frivolous, while others thought they brightened the page. We took all comments into account and revised the page to answer as many comments as possible. In response to a request from one of our reference librarians, for example, we added a link the library's style guide tutorial.
We also made a variety of small changes to the layout and organization of the page.

\section{Response to the Student Assistants' Facebook Group}

Monitoring reactions to the student assistants' Facebook group required a different approach. A survey seemed uncalled for, since there were only a half-dozen students involved. The supervisor of the student assistants interviewed each of the students individually, gauging their perceptions of the new system. First, we wanted to make sure that none of the students found the Facebook group intrusive, but all noted that they were Facebook friends before the group was formed. The students unanimously approved of the Facebook group. They find it quicker and easier than email or texting, and they like the sense of community the group offers. Additionally, the students are able to set up a group chat window to discuss issues or concerns, which will automatically be saved in their messages. They are able to share information with the group about recurring questions or problems in Reference Services either in a post on the group wall or by uploading documents or photos. The students have various Facebook notifications set up on their phones and computers, so they do not need to actively check for messages-the message will come up automatically for them. None of the students identified any negatives or drawbacks to the system, and none of the students expressed concern about their privacy.

The student assistants' supervisor finds the Facebook group very useful as well. The students can easily refer back to information or schedules she has posted previously. She can poll the students to find their preferences for activities and schedules. The supervisor likes knowing that the students will receive notifications of postings, and she can tag students to make sure they receive messages meant for them. She also knows when they have viewed posted items. All of this can be done from within her personal Facebook account. Multiple individuals can be designated as group administrators and have full access to these pages, even if the original creator's account is deactivated or deleted. There is no need to create a second account, and the students do not have to friend her (or each other) on Facebook to be a part of the student assistants' Facebook group. If students are concerned about friending their supervisor on Facebook this can be resolved in the privacy settings on Facebook, through which any user can restrict other users' access to their personal posts, pictures, and friends. Students also have the option of creating a second Facebook profile to use with this group exclusively. Since the group is set for members only, schedules and other private information can only be viewed by members of the group.

\section{CONCLUSION}

Taken together, the Reference Home page and the student assistants' Facebook group have significantly improved our 


\section{FEATURE}

ability to communicate news and changes to all members of the reference staff. Both tools have done what we intended them to do, and both have garnered a satisfactory level of acceptance from our reference staff and students.

We believe, moreover, that the simple, practical nature of our system indicates that the results could be generalized to reference services in many libraries with similar communication needs. Throughout development of Reference Home, we sought, for example, to avoid most of the common pitfalls noted in our literature review. While the site can be interactive (via the Google Calendar, the Twitter feed, etc.), its overall success does not require much user participation. Even the popular Reference Transaction Log does not require staff to type anything - they can log their transactions easily and quickly with a few clicks of the mouse. This both saves time and provides richer data than the old pen and paper system. We deliberately included basic and useful features like the transaction log and the room scheduler to encourage adoption, and by embedding them firmly within the librarians' workspace, these tools quickly become familiar parts of the environment.

We also remained strictly focused on our original goal: efficiently expediting communication. This helped avoid feature creep (otherwise we might have replicated the entire contents of the library homepage on our intranet) and forced us to think creatively about the best tools for the job. The repurposing of an existing technology like LibGuides was another great advantage in that our staff did not have to climb a new learning curve to implement needed changes.

The supervisor of our student assistants followed a similar path in creating the student assistant Facebook group. She found no other platform used so frequently and easily by students as Facebook. Furthermore, no other form of social media would allow us to do all the things we could with a Facebook group, while still upholding a closed community in which student communications and schedules remained private. We also recognize potential for further growth through Facebook. We can upload and share media (such as video and audio files), and we can create events to be shared among group members. Facebook also allows users to retrieve past postings easily.

Other apps within Facebook may be of use in the future. Viber, for instance, is a free calling and texting program that can be accessed from Facebook, allowing group supervisors to send out group messages to all members. Other promising alternatives include Shared, an app that allows editing and sharing of files uploaded through Facebook, and Wunderlist2, which provides shared to-do lists in which users can jointly add and check off completed items. These are only a few of the available possibilities, and the list is constantly growing.

\section{FUTURE DEVELOPMENT}

We recognize that the internal communication tools we have developed may not be appropriate to all situations. Our
Facebook group works well for the current group of students, who are all avid Facebook users. Future student assistants may not be as comfortable with this format, however, and we may need to find other methods. Similarly, our Reference Home page depends on the use of a number of specific applications, and changes in the availability or functioning of any of them would necessitate changes in the system as a whole. We trust, nonetheless, that in the current technological environment any systems that disappear will be promptly replaced by something newer and more advanced.

We further acknowledge that these systems are still a work in progress. We embrace the need for continual improvement, with the goal of building stronger communication and working relationships throughout the libraries. We firmly believe we can accomplish this through rigorous, consistent reevaluation of existing instruments and creative development of new ones. We also accept the need to resist the allure of trendy gadgets and stay focused on accomplishing our objectives in a direct, relevant manner. Our hope is that these new forms of communication will continue to become more useful, familiar, and accepted by our staff.

\section{References}

1. Matthew M. Bejune and Sara E. Morris, "The Development of the Virtual Notebook, a Wiki-based Ready Reference Technology," Reference \& User Services Quarterly 50, no. 1 (2010): 27-34.

2. Alison McIntyre and Janette Nicolle, "Biblioblogging: Blogs for Library Communication," The Electronic Library 26, no. 5 (2008): 685, http://dx.doi.org/10.1108/02640470810910701.

3. See, for example, Kristen Costello and Darcy Del Bosque, "For Better or Worse: Using Wikis and Blogs for Staff Communication in an Academic Library," Journal of Web Librarianship 4, no. 2-3 (2010): 154-55, http://dx.doi.org/10.1080/19322909.2010 .502877; Julia Rodriguez, "Social Software in Academic Libraries for Internal Communication and Knowledge Management: A Comparison of Two Reference Blog Implementations," Internet Reference Services Quarterly 15, no. 2 (2010): 118, http://dx.doi .org/10.1080/10875301003788323.

4. Costello and Del Bosque, "For Better or Worse," 155.

5. Robert Slater, "Reference Desk Notes," Internet Reference Services Quarterly 11, no. 3 (2006): 77, http://dx.doi.org/10.1300/ J136v11n03_05; Rodriguez, "Social Software in Academic Libraries," 119.

6. Jason J. Battles, "Designing and Building a Collaborative Library Intranet for All," Journal of Web Librarianship 4, no. 2-3 (2010): 262, http://dx.doi.org/10.1080/19322909.2010.500570.

7. Costello and Del Bosque, "For Better or Worse," 151.

8. Tammy Ravas, "Not Just a Policies and Procedures Manual Anymore: The University of Houston Music Library Manual Wiki," Notes 65, no. 1 (2008): 38-52, http://dx.doi.org/10.1353/ not.0.0045

9. See, for example, Bejune and Morris, "The Development of the Virtual Notebook," 32-33.

10. Ellie Dworak and Keven Jeffery, "Wiki to the Rescue: Creating a Dynamic Intranet," Library Hi Tech 27, no. 3 (2009): 408-9, http://dx.doi.org/10.1108/07378830910988531.

11. Battles, "Designing and Building a Collaborative Library Intranet for All," 262; Ravas, "Not Just a Policies and Procedures Manual Anymore," 40. 


\section{APPENDIX. SURVEY OF LIBRARIAN REACTION TO REFERENCE}

\section{Home Page Survey of Reaction to New Reference Home Page}

\section{WKU Libraries: Reference Services}

This a brief survey about the Reference Home page. We would like your candid input about its effectiveness.

The survey results will be used to make improvements, so please let us know of any revisions you would like to see. We can't guarantee that we will be able to fulfill every wish, but we will certainly try.

Thanks for your time and your valuable input!

1. On a scale of 1 to 10 , how useful is the Reference Home page?

2. Which of the following do you use or access through the Reference Home page?

- Access to WKU Library Database list

- Emergency procedures

- Passwords for guest computer access

- Passwords for databases and other library resources

- Library phone directory

- Reference transaction log

- Virtual ready reference

- Library room reservation System

- Reference desk calendar

- Reference desk news and updates

3. Do you enter reference transactions through the transaction log on the Reference Home page? Yes/No

4. In your estimation, roughly what percentage of reference transactions are you entering on the log?
a. $100 \%$
b. $90 \%$
c. $80 \%$
d. $70 \%$
e. $60 \%$
f. $50 \%$
g. less than $50 \%$

5. The best thing about the Reference Home page is: (type answer in space provided)

6. The thing I really dislike about the Reference Home page is: (type answer in space provided)

7. What would you like to see added to the Reference Home page? (type answer in space provided)

8. Anything else you would like to say about the Reference Home page? (type answer in space provided)

Thank you for completing the survey ... it is a great help to us as we upgrade and develop the Reference Home page! 